\title{
Suppressive effect of olive residue and saprophytic fungi on the growth of Verticillium dahliae and its effect on the dry weight of tomato (Solanum lycopersicum L.)
}

\author{
C. Arriagada ${ }^{1 *}$, M. García-Sanchez ${ }^{2}$, R. Díaz ${ }^{2}$, I. Sampedro ${ }^{2}$, E. Aranda², I. García-Romera ${ }^{2}$ \\ and J.A. Ocampo ${ }^{2}$ \\ ${ }^{1}$ Laboratorio de Biorremediación, Center of Amelioration and Sustainability of volcanic soils. Scientific and \\ Technological Bioresource Nucleus (BIOREN), Universidad de La Frontera. Casilla 54-D, Temuco, Chile. \\ ${ }^{2}$ Estación Experimental del Zaidín, Consejo Superior de Investigaciones Cientificas, Profesor Albareda 1, \\ 18008 Granada, España. ${ }^{*}$ Corresponding author: cesararriagada@ufro.cl
}

\begin{abstract}
The saprophytic fungi Aspergillus niger, Coriolopsis rigida, Fusarium lateritium, F. oxysporum, Mucor racemosus, Paecilomyces farinosus, Penicillium chrysogenum, P. restrictum, Trametes versicolor, Trichoderma harzianum, T. pseudokoningii and T. viride were able to decrease the growth in vitro of Verticillium dahlie in the presence of aqueous extract of olive residue. The conidia number of $V$. dahliae decreased when grown on aqueous extract of olive residue, autoclaved or filtered through 0.45 micron filters after culture of the fungi. These results suggest not only the predominance of suppressive substances of a biological nature, but also the existence of nonbiological inhibitory substances. The olive residue decreased the negative effect of $V$. dahliae on shoot and root dry weight of tomato (Solanum lycopersicum L.), by the antifungal compounds present in the olive residue and by the antifungal substances produced by the antagonistic saprophytic fungi grown in this residue.
\end{abstract}

Keywords: crop residue, fungal antagonism, fungal exudates, phytotoxicity, antifungal compounds. 


\section{Introduction}

Verticillium dahliae Kleb. is a destructive vascular wilt-causing fungus with worldwide distribution. In recent years, the spread of Verticillium wilt in crops, especially in olive orchards, caused by the soil-borne pathogen $V$. dahliae, is often related to intensive modern farming of highly productive cultivars, planted at high densities, usually irrigated, and under a mechanised system (Rodríguez et al., 2011). The disease causes serious economic losses to a large number of crops. There are no chemical treatments to control it. Thus, management strategies are focused on preventive measures; among those is the use of biological control practices, crop residues or compost soil amendments (Tjamos, 2000; Termorshuizen et al., 2006; Goicoechea et al., 2010). Several antagonistic fungi applied either alone or together with compost significantly reduced the inoculum density of $V$. dahliae in the soil (Lima et al., 2008; Pantelides et al., 2009; Pascual et al., 2009).

The importance of the olive mill industry in Mediterranean countries is well known and it is rapidly extending over other countries such as Australia, Chile, US and so on (D'Annibale et al., 2006). The two-phase extraction system is the most widely used technology to obtain oil and generates a semi-solid organic waste (alpeorujo) which is then dried and further extraction is carried out using solvents to obtain an extra yield of oil and a dry olive mill residue (Vlyssides et al., 1998). Due to its content of organic matter and mineral nutrients, this olive residue might be employed for agronomic purposes (Paredes et al., 1999; Bonanomi et al., 2006). Studies carried out with olive residue have shown that it has antimicrobial and phytotoxic properties (Moreno et al., 1987; Perez et al., 1992; Martín et al., 2002). A decrease in the phytotoxic effect of the olive residue can be achieved by inoculation with saprophytic fungi (Aranda et al., 2007;
Sampedro et al., 2008). Saprophytic fungi are able to mobilize nutrients, to degrade phytotoxic substances and to promote a more efficient use of the nutrients by the plant (Fracchia et al., 2000). Some of the saprophytic fungi used in detoxification of olive residues, such as Trichoderma, and Fusarium have been used as antagonists against $V$. dahliae (Lima et al., 2008; Pantelides et al., 2009).

The aim of this work is to study the potential of olive residue to control Verticillium wilt of tomato, applied either alone or together with saprophytic fungi selected as antagonists of $V$. dahliae.

\section{Material and methods}

\subsection{Materials}

Olive mill dry residue was collected from an olive oil manufacturer (Sierra Sur S.A., Granada, Spain) and stored at $-20{ }^{\circ} \mathrm{C}$ until use. The main characteristics of olive residue were as follows: total organic carbon, $58.5 \%$; total nitrogen, $1.87 \%$; total phosphorus, $0.21 \%$; lignin, $24.7 \%$; cellulose, $18 \%$; hemicellulose, $11.4 \%$; total phenols, $2.65 \%$; total lipids, $0.2 \%$. The most abundant elements, the concentration in $\mathrm{g}$ $\mathrm{kg}^{-1}$ olive residue were: potassium, 30.5; calcium, 13.6; magnesium, 3.8; iron, 1.1; sodium, 0.17; copper, 0.07; zinc, 0.06 and manganese, 0.04. Aqueous extracts from olive mill dry residue were obtained by orbital-shaking of olive mill dry residue with distilled water in a proportion of 1:2(w/v) for $8 \mathrm{~h}$. The $\mathrm{pH}$ of the aqueous extract of the olive residue was 5.13. The extract obtained was filtered through several layers of cheesecloth; and this filtrate was used as a growth medium.

Seventy-one isolates from the genera: Aspergillus (11 species); Coriolopsis (2 species); Fomes (1 spe- 
cies); Fusarium (13 species); Mortierella (3 species); Mucor (3 species); Paecilomyces (2 species); Penicillium (10 species); Phanerochaete (1 species); Phlebia (2 species); Pleurotus (1 species); Poria (3 species); Pycnoporus (1 species); Trametes (4 species); Trichoderma (10 species) and Wardomyces (4 species) genera were selected to test their antagonism against Verticillium dahliae Kleb. EEZ2 (in vitro experiments). These fungi were grown on potato dextrose agar (PDA) slants at $25^{\circ} \mathrm{C}$ for 7 days. Stock cultures of the fungi were stored in PDA slants at $4^{\circ} \mathrm{C}$. Strains were provided by the Centro de Investigaciones Biológicas, CIB (Madrid, Spain), the University of Buenos Aires (Argentina) and by the fungal culture collection of the Estación Experimental del Zaidín (Granada, Spain).

\subsection{In vitro experiments. Evaluation of saprophytic fungal antagonism to $V$. dahliae}

The inhibitory ability of the saprophytic fungal strains against $V$. dahliae was evaluated by using the technique described by Ortiz and Orduz (2001). A plug of $V$. dahliae culture was transferred to a Petri dish containing PDA. After incubation in the darkness at $25^{\circ} \mathrm{C}$ a $4 \mathrm{~mm}$ plug cut out from the margin of a 5-dayold colony was transferred to plates with $15 \mathrm{~mL}$ PDA amended with $1.5 \mathrm{~mL}$ of aqueous extract of olive residue. The plates were incubated for 3 days and after that each antagonist strain was transferred $3 \mathrm{~cm}$ apart from of the $V$. dahliae. The dual cultures were incubated for 11 days under the same conditions and tested for in-vitro antagonistic activity against $V$. dahliae. Ten replicates were set for each treatment and cultures were evaluated macroscopically every $48 \mathrm{~h}$. Centerwise growth of antagonist and $V$. dahliae, determined as influenced mycelial growth radius (internal halo) and edge-wise growth, as free mycelial growth radius (external halo) was measured. Inhibition of fungal growth was calculated using the formula: $(\mathrm{Mb}-\mathrm{Ma}$
/ $\mathrm{Mb}) \times 100$, where $\mathrm{Ma}=$ influenced mycelial growth, $\mathrm{Mb}=$ free mycelial growth. Plates with $V$. dahliae plus $V$. dahliae slants were used as control.

The percent mycelial growth inhibition of $V$. dahliae caused by antagonistic fungal strains was also evaluated on $15 \mathrm{~mL}$ PDA plus $1.5 \mathrm{~mL}$ of aqueous extract of olive residue as described before.

The antagonism of saprophytic fungi to $V$. dahliae grown in aqueous extract of olive residue was also evaluated. The saprophytic fungi and $V$. dahliae were grown individually in Erlenmeyer flasks $(100 \mathrm{~mL})$ containing $10 \mathrm{~mL}$ of aqueous extracts of the olive residue for 15 days at $25{ }^{\circ} \mathrm{C}$ with orbital-shaking at $125 \mathrm{rpm}$. Each flask was inoculated by transferring a 4-mm plug cut out from the margin of a 5-day-old colony. The culture liquid was separated from the mycelium by centrifugation ( $8000 \mathrm{rpm} 15 \mathrm{~min}$ ) and the supernatant was retained. Tubes with $3 \mathrm{~mL}$ of aqueous extracts supernatant were autoclaved $\left(120^{\circ} \mathrm{C}, 20 \mathrm{~min}\right)$ or either filtered by $0.45 \mu \mathrm{m}$ pore size (Millipore). To these tubes was added to $9 \mathrm{~mL}$ of fresh aqueous extracts plus $1 \mathrm{~mL}$ of a suspension of $1 \times 10^{6}$ conidia $\mathrm{mL}^{-1}$ of $V$. dahliae. The aqueous extract from olive residue without saprophytic fungi was used as control. Ten replicates tubes were prepared for each treatment. The tubes were incubated for 3 days at $25^{\circ} \mathrm{C}$ and the number of verticillate spore-bearing structures (conidia), and near-synchronous development of microsclerotia of $V$. dahliae was estimated using the Neubauer chamber (Neumann and Dobinson, 2003).

\subsection{Phytotoxicity experiments}

The effect of the olive residue, alone and together with the saprophytic fungi Penicillium chrysogenum, Fusarium lateritium and C. rigida, on the growth of tomato (Solanum lycopersicum L. cv. Craigella susceptible to Verticillium wilt), cultured in presence of $V$. dahliae was tested. The soil was collected from the 
field of the Estación Experimental del Zaidín (Grana$\mathrm{da}$, Spain). It was a loamy soil. The soil $\mathrm{pH}$ which was measured by glass electrode in a 1:1 soil:water suspension. The $\mathrm{P}\left(\mathrm{NaHCO}_{3}\right.$-extractable), $\mathrm{N}, \mathrm{K}, \mathrm{Fe}, \mathrm{Mn}, \mathrm{Cu}$ and $\mathrm{Zn}$ were determined by methods of Lachica et al. (1965). The main characteristics of the soil are showed in Table 1. The experiments were carried out in $0.3 \mathrm{~L}$ pots containing steam-sterilized soil and quartz sand mixed in a 1:1 ratio $(\mathrm{v} / \mathrm{v})$. The saprophytic fungi incubated in potato dextrose broth (PDB) or in aqueous extract of olive residue were filter-sterilized as described above and $30 \mathrm{~mL}$ were added to soil-sand mixture. An aqueous suspension of $V$. dahliae in sterile distilled water, containing approximately $7 \times 10^{6}$ spore $\mathrm{mL}^{-1}$ was prepared from cultures grown in PDA for one week at $25^{\circ} \mathrm{C}$ and $30 \mathrm{~mL}$ of this suspension were added to pots with soil-sand mixture. The aqueous extract from olive residue or the PDB medium without fungi were used as control. Germinated tomato seeds were selected for uniformity prior to planting. Plants were grown in a greenhouse with natural light supplemented by Sylvania incandescent and cool-white lamps giving 400 $\mathrm{nmol} \mathrm{m} \mathrm{m}^{-1}$ at $400-700 \mathrm{~nm}$; there was a 16-8 h lightdark cycle at $25-19{ }^{\circ} \mathrm{C}$ and $50 \%$ relative humidity. Plants were watered from below, and fed with a nutrient solution at $10 \mathrm{~mL}$ per week (Hewitt, 1952). Pots without extract of olive residue or PDB application, as well as pots with soil-sand mixture inoculated only with an aqueous suspension of $V$. dahliae in sterile distilled water were also used. Plants were inoculated at the time of transplanting. Plants were harvested after 4 weeks and dry matter weight was determined.

Table 1. Chemical characteristics of soil sample.

\begin{tabular}{ccccccccc}
\hline $\mathbf{p H}$ & $\mathbf{O M}$ & $\mathbf{N}$ & $\mathbf{P}$ & $\mathbf{K}$ & $\mathbf{F e}$ & $\mathbf{M n}$ & $\mathbf{C u}$ & $\mathbf{Z n}$ \\
\hline & $\mathrm{g} / \mathrm{kg}^{-1}$ & $\mathrm{mg} / \mathrm{kg}$ & $\mathrm{mg} / \mathrm{kg}$ & $\mathrm{mg} / \mathrm{kg}$ & $\mathrm{mg} / \mathrm{kg}$ & $\mathrm{mg} / \mathrm{kg}$ & $\mathrm{mg} / \mathrm{kg}$ & $\mathrm{mg} / \mathrm{kg}$ \\
8.1 & 19.7 & 2.5 & 6.2 & 132 & 9.6 & 110 & 5.8 & 5.7 \\
\hline
\end{tabular}

OM: Organic matter

\subsection{Experimental design and statistical analysis}

A design $2 \times 2 \times 4$ full factorial completely randomized experimental design was used. We studied the three main factors: Amendment: extract of olive residue and $\mathrm{PDB}$, pathogen fungus: control and $V$. dahliae; and biocontrol agent: control, P. chrysogenum, F. lateritium and C. rigida. Four replicate pots per treatment were used. The data were analysed by factorial analysis of variance with Amendment, pathogen fungus, biocontrol agent and their interaction as sources of variation. Statistical procedures were carried out with the SPSS software, version 11.0
(SPSS Inc., 1989-2001). Statistical significance was evaluated at alpha $=0.05$. Data sets were tested for normality and equal variance (Kolmogorov Smirnov and Cochran's C test, respectively) and a log transformation was applied when significant departures from normality were found. Each experiment was repeated at least twice.

\section{Results}

The percent mycelial growth inhibition of $V$. dahliae grown in PDA medium in the presence of $V$. dahliae was $2.8 \pm 0.8$. From the 71 saprophytic fungi tested, the percent mycelial growth inhibition of $V$. dahliae 
increased significantly in presence of the saprophytic fungi Aspergillus niger-BAFC341 (7.9 \pm 1.2$)$, Coriolopsis rigida-CECT20449 (35.2 \pm 4.9$)$, Fomes sclerodermus-EEZ12 (5.5 \pm 1.4$)$, Fusarium lateritium-BAFC2317 (30.2 \pm 3.2$),$ F. oxysporumBAFC126

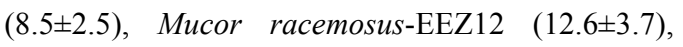
Paecilomyces farinosus-BAFC8846 $\quad(25.7 \pm 4.3)$, Penicillium chrysogenum-EEZ10 (32.4 \pm 5.3$), \quad P$. restrictum-BAFC512 (8.5 1.1$), \quad$ Phanerochaete chrysosporium-ATCC24725 (4.3 \pm 0.4$)$, Phlebia radiata-CBS20448 (5.3 \pm 0.8$)$, Pleurotus ostreatus-EEZ5 (6.1 \pm 0.3$)$, Trametes versicolor-A136 (15.2 \pm 3.3$)$,

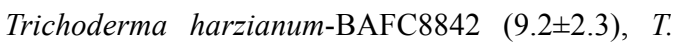

pseudokoningii-BAFC8844 (12.4 \pm 1.3$)$ and T. virideBAFC8850 (11.3 \pm 1.2$)$.

Figure 1 shows that $A$. niger, $C$. rigida, F. lateritium, F. oxysporum, M. racemosus, $P$. farinosus, $P$. chrysogenum, P. restrictum, T. harzianum, T. pseudokoningii, T. versicolor and T. viride were antagonistic against $V$. dahliae grown in PDA medium plus aqueous extract of dry olive mill residue. These fungi produced different degrees of inhibition of the $V$. dahliae mycelial growth. The saprophytic fungi $P$. chrysogenum, F. lateritium, C. rigida and P. farinosus showed the highest and statistically significant inhibitory effect on $V$. dahliae mycelial growth when compared to the other antagonist strains (Figure 1).

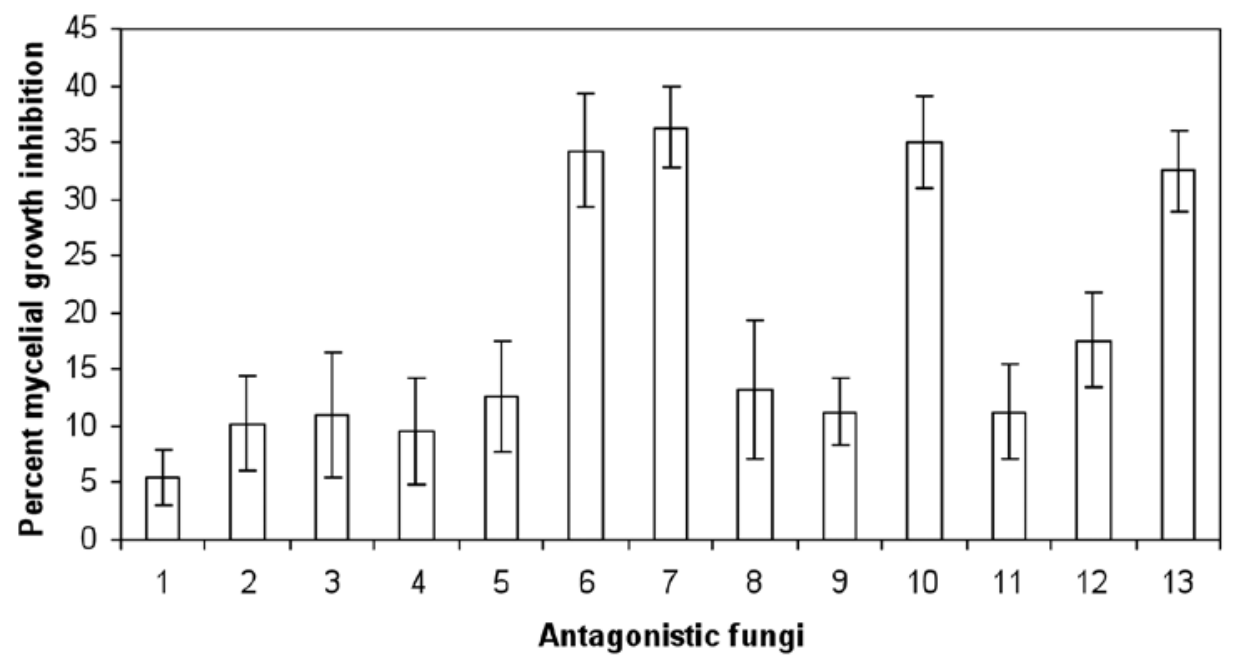

Figure 1. Percent mycelial growth inhibition of Verticillium dahliae in presence of $V$. dahliae and of antagonistic saprophytic fungi cultivated in PDA medium plus aqueous extract of olive residue. $1=V$. dahliae, $2=$ Trichoderma harzianum, 3=Aspergillus niger, 4=Trametes versicolor, 5=Trichoderma viride, 6=Penicillium chrysogenum, 7=Coriolopsis rigida, 8=Trichoderma pseudokoningii, 9=Mucor racemosus, 10=Fusarium lateritium, $11=$ Fusarium oxysporum, 12=Penicillium restrictum, 13=Paecilomyces farinosus. The data are shown as mean \pm standard error of the mean. 
The aqueous extract of olive residue autoclaved or filtered with Millipore after its incubation with $V$. dahliae or without saprophytic fungi incubation (Control), had the same effect on the number of $V$. dahliae conidia and microsclerotia. Thus we included only the values of the control treatment in Figure 2. The filtered aqueous extract of olive residue autoclaved after its incubation with $T$. viride, F. lateritium, F. oxysporum or $C$. rigida reduced the number of conidia and microsclerotia of $V$. dahliae (Figure 2a). The filtered aqueous extract of olive residue after its incubation with $P$. chrysogenum, F. lateritium or $C$. rigida significantly reduced the number of $V$. dahliae conidia and microsclerotia (Figure 2b).

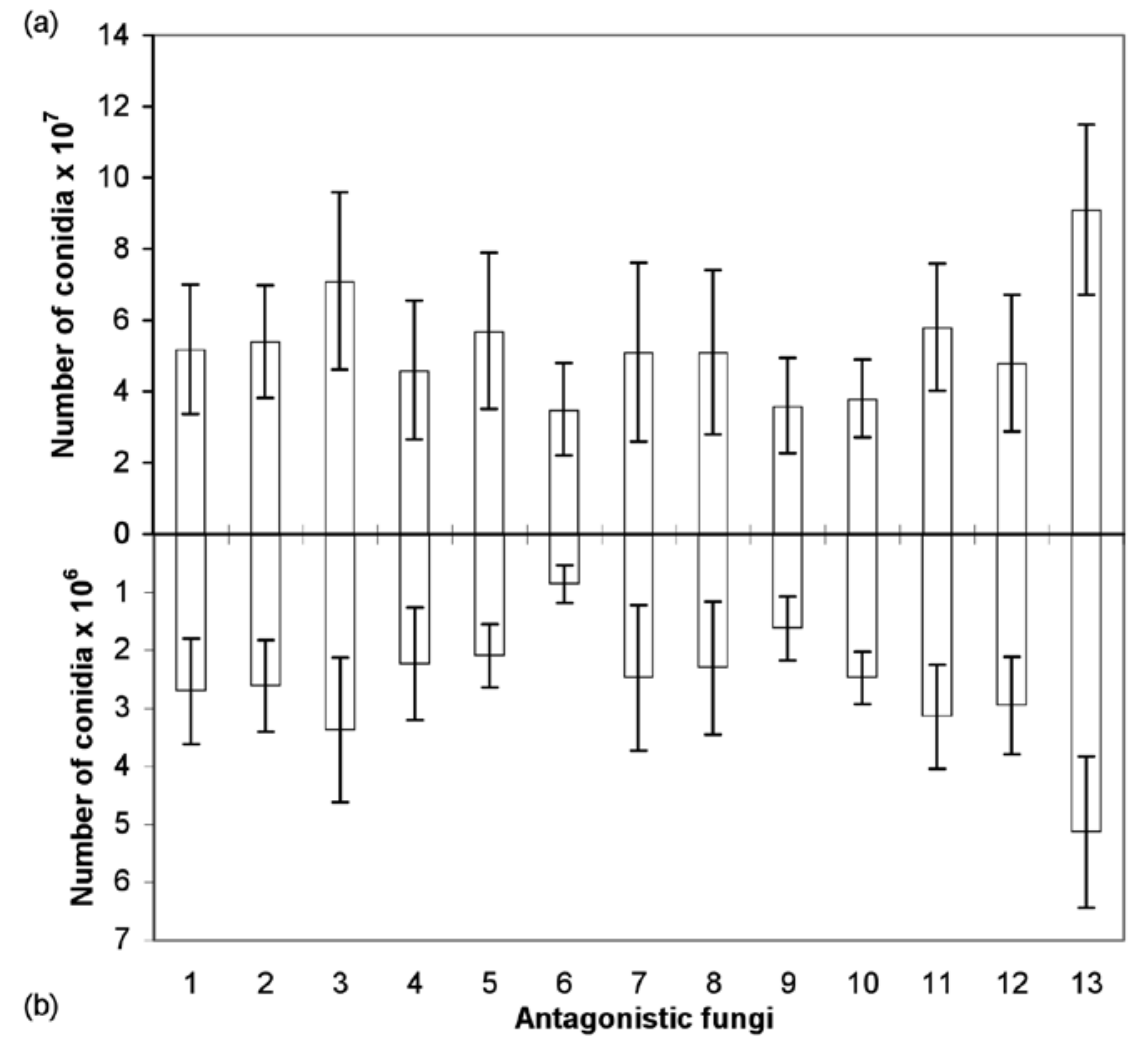

Figure 2. Number of Verticillium dahliae conidia grown in (a) autoclaved or (b) filtered aqueous extract of olive residue after its incubation with of the antagonistic fungi. 1=Trichoderma harzianum, $2=$ Aspergillus niger, $3=$ Trametes versicolor, $4=$ Trichoderma viride, $5=$ Penicillium chrysogenum, $6=$ Coriolopsis rigida, $7=$ Trichoderma pseudokoningii, 8=Mucor racemosus, 9=Fusarium lateritium, 10=Fusarium oxysporum, 11=Penicillium restrictum, 12=Paecilomyces farinosus, 13=Uninoculated control. The data are shown as mean \pm standard error of the mean. 
Symptoms of Verticillium wilt were observed during the experiment and vascular browning was found in the plant tissues. However, the influence of the pathogen was measured as the reduction of shoot and root dry weight of the plant infected with the pathogen in comparison to the untreated control. As Table 2 shows, there were significant differences in the means of the response variables (shoot dry weight), to all the levels and main factors (Amendment, $p=0.00063$; pathogen fungus, $p=0.00087$ and BCA, $p=0.00058$ ) tested. The contrasts between the factors amendment, pathogen fungus and BCA ( $p=0.00063)$, between the factors amendment and pathogen fungus $(p=0.00065)$, as well as between the factors amendments and BCA ( $p=0.025$ ) were statistically significant for both the response variables. The application of aqueous extract of olive residue decreased the shoot and root dry weight of tomato (Figure 3). The decrease of the shoot and root dry weight of tomato caused by inocu- lation with $V$. dahliae suspended in water or in PDB were significantly greater than when the pathogen was inoculated in a suspension of an aqueous extract of olive residue. The saprophytic fungi $P$. chrysogenum, $F$. lateritium and $C$. rigida were able to decrease the toxicity of aqueous extract of olive residue on tomato, but none of them were able to eliminate the phytotoxicity caused by this residue. The saprophytic fungi cultivated in aqueous extract of olive residue or PDB decreased, but did not eliminate, the negative effect caused by $V$. dahliae on the shoot and root dry weight of tomato The shoot and root dry weight of tomato inoculated with $V$. dahliae grown in aqueous extract of olive residue plus exudates of the saprophytic fungi, were similar to plants grown in presence of aqueous extract of olive residue. However, the shoot and root dry weights of tomato inoculated with PDB, were higher than those of plants inoculated with $V$. dahliae grown in PDB plus exudates of the saprophytic fungi.

Table 2. Significance of the main treatment effects and their interactions based on factorial analysis of variance.

\begin{tabular}{|c|c|c|c|c|c|c|c|}
\hline & \multicolumn{7}{|c|}{ F-values } \\
\hline & $\mathbf{A}$ & $\mathbf{P}$ & BCA & & & & \\
\hline & $\begin{array}{l}\text { Amend- } \\
\text { ment }\end{array}$ & $\begin{array}{l}\text { Pathogen } \\
\text { fungus }\end{array}$ & $\begin{array}{l}\text { Biocontrol } \\
\text { Agent }\end{array}$ & $A \times P$ & A $x$ BCA & P $\times$ BCA & $\begin{array}{l}\text { Ax Px } \\
\text { BCA }\end{array}$ \\
\hline $\begin{array}{l}\text { Shoot dry } \\
\text { weight }\end{array}$ & $30.82 * * *$ & $235.37 * * *$ & $8.45^{* * *}$ & $29.46 * * *$ & $3.51 *$ & $10.69 * * *$ & $10.85^{* * *}$ \\
\hline
\end{tabular}

A: soil pot with Amendment; P: Pathogen fungus; BCA: Biocontrol agent.

$*: p<0.05$

$* * *: p<0.001$ 


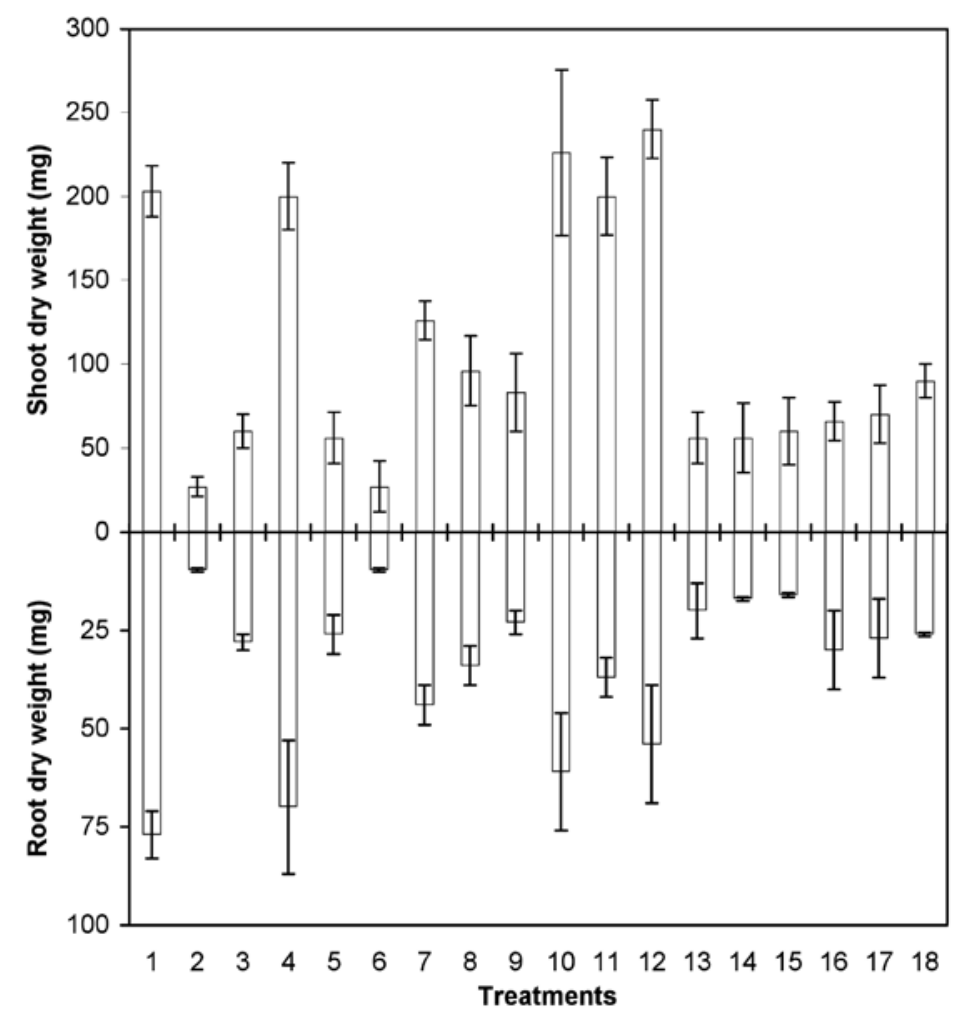

Figure 3. Shoot and root dry weight of tomato (Solanum lycopersicum L.) inoculated with Verticillium dahliae and cultivated in presence of exudates from the antagonistic saprophytic fungi grown in olive residue or in potato dextrose broth (PDB) medium. $1=$ Uninoculated controls, 2=Plants inoculated $V$. dahliae, $3=$ =Plants inoculated with aqueous extract of olive residue, 4=Plants inoculated with PDB, 5=Plants inoculated with aqueous extract of olive residue plus $V$. dahliae, 6=Plants inoculated with PDB plus $V$. dahliae, 7, 8 and 9=Plants inoculated with exudates of Penicillium chrysogenum, Coriolopsis rigida and Fusarium lateritium grown in aqueous extract of olive residue, respectively, 10,11 and 12=Plants inoculated with exudates of $P$. chrysogenum, C. rigida and F. lateritium grown in PDB, respectively, 13, 14 and 15=Plants inoculated with $V$. dahliae plus exudates of $P$. chrysogenum, $C$. rigida and $F$. lateritium grown in aqueous extract of olive residue, respectively, 16, 17 and 18=Plants inoculated with $V$. dahliae plus exudates of $P$. chrysogenum, $C$. rigida and F. lateritium grown in PDB, respectively. The data are shown as mean \pm standard error of the mean.

\section{Discussion}

Most of the studies on antagonistic microorganisms against $V$. dahliae have been focussed on soil fungi belonging to Trichoderma, Paecylomices, Penicil- lium, Fusarium and Talaromyces genera (Tjamos and Fravel, 1995; Berg et al., 2005; Lima et al., 2008; Naraghi et al., 2008; Pantelides et al., 2009). We found isolates belonging to the genera Aspergillus, Coriolopsis, Fomes, Mucor, Phanerochaete, Phlebia, Pleu- 
rotus and Trametes that also have antagonistic effect against $V$. dahliae in vitro and can be useful in reducing Verticillium wilt in conditions where other fungi were not effective antagonists. Exudates produced by fungi antagonistic to $V$. dahliae seem to be the responsible of the antagonistic effect of crop residues on the density of $V$. dahliae in the soil and on the Verticillium wilt (Lima et al., 2008; Pantelides et al., 2009). The antagonistic fungi $A$. niger, $C$. rigida F. lateritium, F. oxysporum, M. racemosus, $P$. chrysogenum, P. restrictum, P. farinosus, T. versicolor, T. harzianum, $T$. pseudokoningii, and T. viride were able to decrease the growth in vitro of $V$. dahlie the presence of aqueous extract of olive residue. Several studies have demonstrated the loss of disease suppression of composts following sterilisation or pasteurisation (Cotxarrera et al., 2002; Reuveni et al., 2002). Therefore, in these instances the suppressive effect was predominantly biological rather than chemical or physical in nature (Noble and Coventry, 2005; Malandraki et al., 2008). We found that the aqueous extract of olive residue filtered after its incubation with $C$. rigida, F. lateritium, $P$. chrysogenum and $P$. farinosus decreased the number of $V$. dahliae conidia and microsclerotia indicating the presence of suppressive substances of biological origin. However, we also found that the aqueous extract of olive residue autoclaved after its incubation with $C$. rigida, $F$. lateritium, $F$. oxysporum and $T$. viride decreased the number of $V$. dahliae conidia and microsclerotia. On the other hand, our results shows that the aqueous extract of olive residue non-inoculated with saprophytic fungi also decreased the negative effect of $V$. dahliae on the growth of tomato. These results indicate the existence of other kind of thermoresistant inhibitory compounds in the aqueous extract of olive residue. In fact, studies carried out with olive residues have shown that it has notable antimicrobial properties mainly due to its phenolic content (Moreno et al., 1987; Perez et al., 1992). The existence of some saprophytic fungi that can change the chemical structure of the phenolic compounds of the olive residue have been also found (Aranda et al., 2007; Sampedro et al., 2007). However, the possibility of the implication of the phenolic compounds in the antagonistic effect of the aqueous extract of olive residue on $V$. dahliae remains to be investigated. The exudates produced by the saprophytic fungi grown in the aqueous extract of olive residue also decreased the pathogenesis of $V$. dahliae against tomato. The possible joint actions between the antifungal compounds that have the aqueous extract of olive residue and the antifungal substances produced by the saprophytic fungi grown in this olive residue, may explain why the effectiveness of this residue with the fungal exudates on the damage caused by $V$. dahliae on tomato was higher than of the PDB with the antagonist fungal exudates.

On the other hand, it is known that the olive residue is toxic to plants and that the content of monomeric phenols of the olive residue seems to be responsible for phytotoxic properties (Martín et al., 2002). Reductions of the phytotoxic effect of olive residue by the use of saprophytic fungi that decrease its phenolic content have been found (Aranda et al., 2007; Sampedro et al., 2008). The saprophytic fungi $P$. chrysogenum, F. lateritium and $C$. rigida, which were antagonistic in vitro to $V$. dahliae, also decrease the phytotoxicity of aqueous extract of olive residue on shoot and root dry weight of tomato.

\section{Conclusions}

We demonstrated in this work, that the olive residue decreased the negative effect of $V$. dahliae on the growth of tomato (Solanum lycopersicum L.), by the antifungal compounds present in the olive residue and by the antifungal substances produced by the antagonistic saprophytic fungi grown in this residue. The use of olive residues incubated with specific isolates of 
several saprophytic fungi open possible ways towards its use in agriculture and the possibility of its future use in the biological control of Verticillium wilt of tomato; however, more investigation is necessary.

\section{Acknowledgements}

Financial support of this study was provided by the Dirección de Investigación Universidad de La Frontera, project $\mathrm{N}^{\circ} \mathrm{DI} 09-4002$ international cooperation.

\section{References}

Aranda E., García-Romera I., Ocampo J.A., Carbone V., Malorni A., Sannino F., De Martino A., Capasso R. 2007. Chemical characterization and effects on Lepidium sativum of the native and bioremediated components of dry olive mill residue. Chemosphere. 69, 229-239.

Berg G., Zachow C., Lottmann J., Götz M., Costa R., Smalla K. 2005. Impact of plant species and site on rhizosphere-associated fungi antagonistic to Verticillium dahliae Kleb. App Environ Microbiol. 71, 4203-4213.

Bonanomi G., Giorgi V., Del Sorbo G., Neri D., Scala F. 2006. Olive mill residues affect saprophytic growth and disease incidence of foliar and soilborne plant fungal pathogens. Agric Ecosyst Environ. 115, 194-200.

Cotxarrera L., Trillas-Gay M.I., Steinberg C., Alabouvette C. 2002. Use of sewage sludge compost and Trichoderma asperellum isolates to suppress Fusarium wilt of tomato. Soil Biol Biochem. 34, 467-476.

D'annibale A., Quaratino D., Federici F., Fenice M. 2006. Effect of agitation and aeration on the reduction of pollutant load of olive mill wastewater by the white-rot fungus Panus tigrinus. Biochem Eng J . 29, 243-249.
Fracchia S., García-Romera I., Godeas A., Ocampo J.A. 2000. Effect of the saprophytic fungus Fusarium oxysporum on arbuscular mycorrhizal colonization and growth of plants in greenhouse and field trials. Plant Soil. 223, 175-184.

Goicoechea N., Garmendia I., Sánchez-Díaz M., Aguirreolea J. 2010. Review. Arbuscular mycorrhizal fungi (AMF) as bioprotector agents against wilt induced by Verticillium spp. in pepper. Span J Agric Res. 8, 25-42.

Hewit E.J. 1952. Sand Water Culture Methods Used in the Study of Plant Nutrition. CAB Tech. Co., Farmham Royal, Bucks, United Kindong.

Lachica M., Recalde L., Esteban E., 1965. Métodos analíticos utilizados en la Estación Experimental del Zaidín. Anal Edafol Agrobiol. 24, 589-610.

Lima G., Piedimonte D., De Curtis F., Elgelane A.A., Nigro F., D’onghia A.M., Alfano G., Ranalli G. 2008. Suppressive effect of cured compost from olive oil by-products towards Verticillium dahliae and other fungal pathogens. Acta Hort. 791, 585591.

Malandraki I., Tjamos S.E., Pantelides I.S., Paplomatas E.J. 2008. Thermal inactivation of compost suppressiveness implicates possible biological factors in disease management. Biol Control. 44, 180-187.

Martín J., Sampedro I., García-Romera I., GarcíaGarrido J.M., Ocampo J.A. 2002. Arbuscular mycorrhizal colonization and growth of soybean (Glycine maximum) and lettuce (Lactuca sativa) and phytotoxic effects of olive mill residues. Soil Biol Biochem. 34, 1769-1775.

Moreno E., Perez J., Ramos-Cormenzana, A., Martinez J. 1987. Antimicrobial effect of wastewaters from olive oil extraction plants selecting soil bacteria after incubation with diluted waste. Microbios. 51, 169-174. 
Naraghi L., Heydari A., Azaddisfani F. 2008. Effects of non-volatile extracts of Talaromyces flavus on cotton Verticillium Wilt disease. Asian J Plant Sci. 7, 389-393.

Neumann, M., Dobinson, K. 2003. Sequence tag analysis of gene expression during pathogenic growth and microsclerotia development in the vascular wilt pathogen Verticillium dahliae. Fung. Genet. Biol. 38, 54-62.

Noble R., Coventry E. 2005. Suppression of soilborne plant diseases with composts: a review. Biocontrol Sci Techn. 15, 3-20.

Ortiz A., Orduz S. 2001. In vitro evaluation of Trichoderma and Gliocladium antagonism against the symbiotic fungus of the leaf-cutting ant Atta cephalotes. Mycopathologia. 150, 53-60.

Pantelides I.S., Tjamos S.E., Striglis I.A., Chatzipavlidis I., Paplomatas E.J. 2009. Mode of action of a non-pathogenic Fusarium oxysporum strain against Verticillium dahliae using Real Time QPCR analysis and biomarker transformation. Biol Control. 50, 30-36.

Paredes C., Cegarra J., Roig A., Sanchez-Monedero M.A., Bernal M.P. 1999. Characterization of olive mil wastewater and its sludge for agricultural purposes. Biores Technol. 67, 111-115.

Pascual I., Azcona I., Morales F., Aguirreolea J., Sánchez-Díaz M. 2009. Growth, yield and physiology of Verticillium-inoculated pepper plants treated with ATAD and composted sewage sludge. Plant Soil. 319, 291-306.

Perez J., De La Rubia T., Moreno J., Martinez J. 1992. Phenolic content and antibacterial activity of olive oil waste waters. Environ Toxicol Chem. 11, 489-495.

Reuveni R., Raviv M., Krasnovsky A., Freiman L., Medina S., Bar A., Orion D. 2002. Compost induces protection against Fusarium oxysporum in sweet basil. Crop Prot. 21, 583-587.
Rodríguez E., García-Garrido J.M., García P.A., Campos M. 2011. Origin of plant propagation, landuse history, and soil properties implications for Verticillium wilt in olive groves. J Plant Pathol. 93, 111-118.

Sampedro I., D’annibale A., Ocampo J.A., Stazi S.R., García-Romera I. 2007. Solid state cultures of Fusarium oxysporum transform aromatic components of olive-mill dry residue and reduce its phytotoxicity. Biores Technol. 98, 3547-3554.

Sampedro I., Aranda E., Diaz R., García-Sanchez M., Ocampo J.A., García-Romera I. 2008. Saprophytic fungi decreased the sensitivity to the toxic effect of dry olive mill residue on arbuscular mycorrhizal plants. Chemosphere. 70, 1383-1389.

Termorshuizen A.J., Van Rijn E., Van der Gaag D.J., Alabouvette C., Chen Y., Lagerlof J., Malandrakis A.A., Paplomatas E.J., Ramerte B., Ryckeboerg J., Steinberg C., Zmora-Nahum S. 2006. Suppressiveness of 18 composts against 7 pathosystems: variability in pathogen response. Soil Biol Biochem. 38, 2461-2477.

Tjamos E.C. 2000. Strategies in developing methods and applying techniques for the biological control of Verticillium dahliae. In: E.C. Tjamos, R.C. Rowe, J.B. Heale, D.R. Fravel. (eds). Advances in Verticillium. Research and disease management. The APS Press, St Paul, MN, USA, pp: 227-231.

Tjamos E.C., Fravel D.R. 1995. Detrimental effects of sublethal heating and Talaromyces flavus on microsclerotia of Verticillium dahliae. Phytopathology. $85,388-392$.

Vlyssides AG., Loizidou M., Gimouhopoulos K., Zorpas, A. 1998. Olive oil processing wastes production and their characteristics in relation to olive oil extraction methods. Fresen Environ Bull. 7, 308-313. 
